\title{
FORECASTING COARSE RICE PRICES IN BANGLADESH
}

\author{
M. F. Hassan*, M. A. Islam ${ }^{1}$, M. F. Imam ${ }^{2}$ and S. M. Sayem ${ }^{3}$ \\ Department of Agricultural Statistics, Bangladesh Agricultural University \\ Mymensingh-2202, Bangladesh
}

\begin{abstract}
Bangladesh being a developing country, always tries to control the market prices of coarse rice for stable political and social condition. The main aim of this paper is to find out appropriate deterministic time series model using the latest selection criteria that could best describe the coarse rice price pattern in Bangladesh during the time period July 1975 to December 2011. A total of 438 secondary data on monthly wholesale prices of coarse rice from July 1975 to December 2011 have been used for time series analysis. In this study growth models of different types are fitted using the software package SPSS 20 for the selected time series. The study reveals that cubic model is the best fitted model for wholesale price of coarse rice on the basis of model selection criterion $\left(R^{2}, \bar{R}^{2}\right.$, RMSE, AIC, BIC, MAE and MAPE). Cubic growth rates varied from $0.68 \%$ to $4.03 \%$. After choosing the best growth model by the model selection criteria the coarse rice prices are forecasted for the time period January 2012 to December 2013.
\end{abstract}

Key Words: Coarse rice, Forecasting, Price

\section{INTRODUCTION}

Bangladesh is predominantly an agriculture based country with more than 149 million people living on 14.84 million hectares of land (FAO, 2011). Economic development of the country is based mainly on agriculture as the contribution of agriculture sector in GDP is $16.03 \%$ (BBS, 2009). Rice is one of the leading food crops to fulfill the demand of carbohydrate in Bangladesh. At present rice is cultivated in 10.58 million hectares of land. It alone constitutes the lion share $(96 \%)$ of total food grain produced in Bangladesh (BBS, 2010). In Bangladesh $63 \%$ of the labor force is directly engaged in agriculture and $78 \%$ of total cropland diverted to rice production (BER, 2010). Since independence food autarky of Bangladesh has become dependent on rice production. All the five year plans had especial emphasis on the production of rice. Most of the people of our country consume coarse

1 Professor, Department of Agricultural Statistics, Bangladesh Agricultural University, Mymensingh-2202, Bangladesh

2 Associate Professor, Department of Agricultural Statistics, Bangladesh Agricultural University, Mymensingh-2202, Bangladesh

3 Lecturer, Department of Agricultural Statistics, Bangladesh Agricultural University, Mymensingh-2202, Bangladesh

* Corresponding author: E-mail: fuad_bau016@yahoo.com 
rice. Aus, Aman and Boro in all the three seasons various varieties of coarse rice are cultivated and produced, and government through various relief operations release mainly coarse rice. Any fluctuation in the price of coarse rice always makes government anxious as the fluctuation in coarse rice price has great impact on the millions of its producers and consumers (Brennan, 1995).

Evaluation of the price pattern of rice in Bangladesh may serve as an aid for policy makers in taking decision regarding production, procurement, export, import etc. To reveal the price pattern and to make the best forecasts of coarse rice price in Bangladesh appropriate time series models that best describe the observed data successfully are necessary. For forecasting purpose two types of time series models are widely used in practice. The first type is known as deterministic time series model and second type is known as stochastic time series model. Among the stochastic time series models Autoregressive integrated moving average model (ARIMA) are very popular as they successfully describe the observed data and make forecast with minimum forecast error. But these types of model are very difficult to identify and also to estimate. If they are not identified correctly then their forecasting performance will be poor. In the mean time, they are very expensive, time consuming and very difficult to understand as the internal mechanism of model building procedure is complex. On the other hand, deterministic type time series models, often called growth models, such as linear, quadratic, cubic, logarithmic, exponential, compound, inverse, power, and S-shaped are very quick to estimate, inexpensive and very easy to understand. Although they do not provide as much forecasting accuracy as the correctly identified and estimated stochastic time series models in many cases they provide a simple, inexpensive still quite acceptable means of forecasting. It is very important to note that these models are called deterministic in that no reference is made to the sources and nature of the underlying randomness in the series (Pindyck et al. 1998). These models are widely used to estimate the growth rate of time series. Before performing growth analysis it is necessary to identify the growth model that best fits the time series. Here, an attempt is made to identify the best models for coarse rice price in Bangladesh using the latest available criteria such as $R^{2}, \bar{R}^{2}$, RMSE, AIC, BIC, MAE and MAPE (Gujarati, 2003). Attempts are also made to describe the growth scenario and to make forecasts of coarse rice price in Bangladesh using the best fitted models.

\section{METHODOLOGY}

\section{Data and models}

The study was conducted using secondary time series data of coarse rice price in Bangladesh for July 1975 to December 2011. The monthly data of the wholesale prices of coarse rice (Tk. per quintal) from the year July 1975 to December 2011 have been collected from Department of Agricultural Marketing, Food Planning and Monitoring Unit (FPMU) of the Ministry of Food System Management Division of the Directorate General of food and other different historical reports published by the government. These secondary data are used to analyze and achieve the specific objectives of the study. 
The growth models are used to describe the behaviour of variable varying with respect to time. In these models integrated variable exhibits a systematic variation or trend. If the trends are completely predictable, it is called as deterministic trend. The specification of a deterministic trend can be any functional form of time. The deterministic trend can be any functional form of the following:

$$
\begin{aligned}
& D T=\alpha+\beta t(\text { Linear trend }) \\
& \left.D T=\sum_{i=0}^{k}=P_{i} t^{i} \text { (Polynomial time trend }\right)
\end{aligned}
$$

It is important to note that these models are called deterministic in that no reference is made to the source and nature of the underlying randomness in the series (Pyndick et al. 1998). For forecasting purpose different deterministic type of time series models are used, also known as growth models. This type of model is needed in specific area of a specific problem that depends on type of growth that occurs in the time series data. Linear, logarithmic, quadratic, cubic, exponential, compound, inverse, power, and S-shaped are well known growth models. In this study five deterministic type growth models are considered for study purpose. These models are: Linear Model, Quadratic Model, Exponential Model, Compound Model and Cubic Model. Table 1 shows the variations among the nature of the different growth rates for different models.

\begin{tabular}{|c|c|c|c|}
\hline $\begin{array}{c}\text { Name of the } \\
\text { model }\end{array}$ & Mathematical form & $\begin{array}{l}\text { Monthly growth rate in } \\
\text { percentage }\end{array}$ & Meaning of notation \\
\hline Linear & $Y_{i}=\alpha+\beta t+\epsilon$ & $\frac{\beta}{r_{t}} \times 100$ & $\begin{array}{l}Y_{t} \text { is the time series } \\
\text { considered }\end{array}$ \\
\hline Quadratic & $y_{t}=\alpha+\beta t+\gamma t^{2}+\epsilon$ & $\frac{\beta+2 \gamma t}{Y_{t}} \times 100$ & t represent time taking \\
\hline Cubic & $Y_{t}=\alpha+\beta t+\gamma t^{2}+\delta t^{3}+\epsilon$ & $\frac{\rho+z_{\gamma} v+a \delta z^{2}}{Y_{t}} \times 100$ & $\begin{array}{l}\text { integers values starting } \\
\text { from } 1\end{array}$ \\
\hline Compound & $Y_{t}=\alpha \beta^{t} e^{E}$ & $(\beta-1) \times 100$ & $\begin{array}{l}\varepsilon \text { is the regression residual } \\
\alpha, \beta, \gamma \text { are the coefficient of }\end{array}$ \\
\hline Exponential & $Y_{t}=\alpha e^{\beta t \varepsilon}$ & $\beta \times 100$ & the model \\
\hline
\end{tabular}

Table 1. Mathematical forms of different growth models and their growth rates

Growth rates for linear, exponential and compound models are independent of time. The growth rate in linear model is constant in its absolute value throughout the time interval in its percentage value. But growth rates for other models depend on time. The basic difference between the exponential and compound model is in the value and interpretation of the value of the $\beta$ coefficients of the two models. Forecast obtained by these models can often be usefully combined with other forecasts in order to get superior overall forecasts.

\section{Model selection criteria}

Model selection is an important part of any statistical analysis. Most of the procedures for choosing between two competing econometric models take the following form: each 
econometric model is estimated by a method that solves some optimization problem; the models are then compared by defining an appropriate goodness-of-fit or selection criterion for each model; and the better-fitting model according to this criterion is selected. In this study several model selection criteria are used which are given in Table 2.

Table 2. Mathematical form of the model selection criterion

\begin{tabular}{|c|c|}
\hline Selection criterion & Notations \\
\hline$A I C=n \log (M S E)+2 K$ & AIC: Akaike Information Criterion \\
\hline$B I C=n \log (M S E)+K \log n$ & BIC: Bayesian Information Criterion \\
\hline$R^{2}=1$ Error sum of square & $R^{2}$ : Coefficient of Determination \\
\hline$\kappa=1-\overline{\text { Total sum of square }}$ & $\bar{R}^{2}:$ Adjusted \\
\hline $\bar{R}^{2}=1-\left(1-R^{2}\right) \frac{n-1}{n-k}$ & $\begin{array}{l}\text { MSE: Mean Squared Error } \\
\text { RMS: Root Mean Square Error }\end{array}$ \\
\hline$M S E=\frac{1}{n-k} \sum \hat{\epsilon}_{t}^{2}$ & $\begin{array}{l}\text { MAE: Mean Absolute Error } \\
\text { MAPE: Mean Absolute Percent Error }\end{array}$ \\
\hline $\begin{array}{l}R M S E=\sqrt{\frac{1}{n-k} \sum \hat{\epsilon}_{t}^{2}} \\
M A E=\frac{1}{n} \sum_{t=1}^{n}\left|\hat{\epsilon}_{t}\right|\end{array}$ & $\begin{array}{l}k \text { is the number of parameters in the } \\
\text { statistical model, } \mathrm{n} \text { is the sample size, } Y_{t} \text { is } \\
\text { the observed value, } \hat{\epsilon}_{t} \text { is the difference } \\
\text { between the observed and estimated values }\end{array}$ \\
\hline$M A P E=\frac{1}{n} \sum_{t=1}^{n}\left|\frac{\hat{\epsilon}_{t}}{Y_{t}}\right| \times 100$ & \\
\hline
\end{tabular}

The model with higher $R^{2}, \bar{R}^{2}$ and minimum AIC, BIC, MSE, MAE, MAPE is assumed to describe the data series adequately.

\section{RESULTS AND DISCUSSION}

\section{Description of the original series}

The line graph in Fig. 1 shows the monthly wholesale prices of coarse rice from July 1975 to December 2011. This reveals the range of data and the time at which the peaks were occurred. The price of one quintal coarse rice was Taka (Tk.) 528 in July 1975. Afterwards price followed an erratic trend from 1975 to 1992. In the September, 1992 the prices suddenly decreased to Taka 967 from Taka 1007 in august, 1992 and then followed a decreasing trend up to January 1994 (Taka 930). Later a wild fluctuation was evident price from March 1994 (at Taka a 1035) to November 2007 (at Taka 2191). Following this prices increased rapidly from December 2007 (at Taka 2266) up to April 2008 (at Taka 3139). Then prices declined sharply from August 2008 at taka 3076 to august 2009 (at Taka 1746). After that the prices went up exponentially from September 2009 (at Taka 1817) to January 
2011and peaked in March 2011 (at Taka 3271.50), then suffered from some fluctuation up to January 2012.

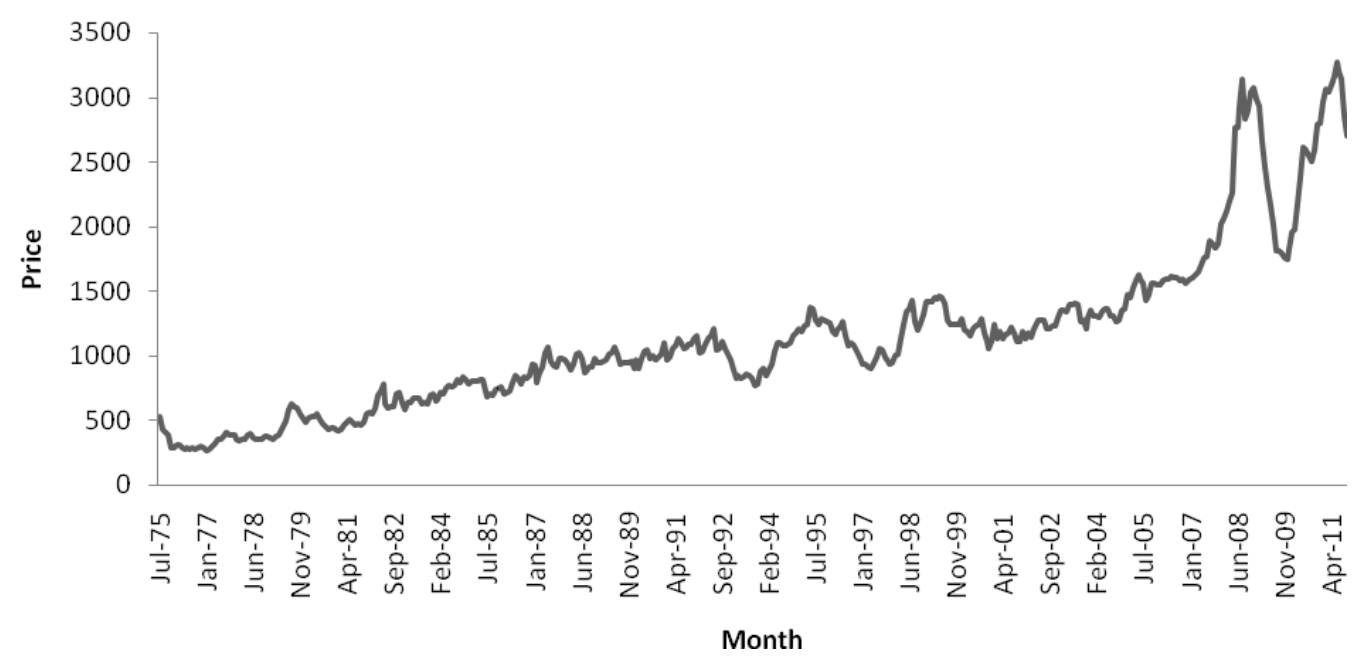

Fig. 1. Wholesale price of coarse rice: Taka per quintal, Monthly data (July 1975-December 2011)

\section{Selecting the best deterministic growth model}

All the model selection criteria that have been used in this study to identify the best fitted model for forecasting purpose and also for explaining the growth patterns are calculated and given in Tables 3 and 4. Interpretation of the model selection criteria considered that the more the value of $R^{2}$, and $\bar{R}^{2}$, the better is the fitness of the model. On the other hand, the smaller is the value of RMSE, AIC, BIC, MAE, and MAPE; the better is the fitness of the model. The estimates of the parameters of the selected time series are given in Table 4 . It is appeared from Table 4 that all the constant term and regression coefficients of quadratic, exponential and compound models are significant at $1 \%$ level and for linear and cubic model these are significant at $5 \%$ level of probability.

Table 3. Parameter estimates of the different growth models of coarse rice price in Bangladesh

\begin{tabular}{lcccc}
\hline \multicolumn{1}{c}{ Model } & $\alpha$ & $\beta$ & $\gamma$ & $\delta$ \\
\hline Linear & $157.029^{*}$ & $4.537^{*}$ & & \\
Quadratic & $510.707^{* *}$ & -0.286 & $0.011^{* *}$ & \\
Compound & $395.189^{* *}$ & $1.004^{* *}$ & & \\
Cubic & 52.463 & $12.169^{*}$ & $-0.06^{*}$ & $.0002^{*}$ \\
Exponential & $395.189^{* *}$ & $0.004^{* *}$ & & \\
\hline
\end{tabular}

$(* *, *$ indicate significant at $1 \%$ and $5 \%$ level of probability respectively) 
It is evident from Table 4 that the value of $R^{2}(0.910)$ and $\bar{R}^{2}(0.899)$ are higher for cubic model compared to the linear, compound, quadratic, and exponential models. The value of RMSE (207.445), AIC (2037.609), BIC (2040.175), MAE (146.774), and MAPE (13.984) are also lower for cubic model compared to other growth models. Thus the cubic model is seemed to be the best not only for describing the growth pattern of coarse rice price in Bangladesh but also for making forecast with minimum forecast error.

Table 4. Criteria of model selections for coarse rice price in Bangladesh

\begin{tabular}{l|c|c|c|c|c|c|c|c}
\hline \multicolumn{1}{c}{ Model } & $R^{2}$ & $\bar{R}^{2}$ & RMSE & AIC & BIC & MAE & MSE & MAPE \\
\hline Linear & 0.773 & 0.772 & 310.650 & 2188.105 & 2189.388 & 211.7199 & 96948.28 & 17.433 \\
Quadratic & 0.831 & 0.830 & 268.002 & 2134.365 & 2136.289 & 214.4533 & 72323.66 & 20.863 \\
compound & 0.881 & 0.881 & 256.925 & 2115.868 & 2117.151 & 195.683 & 66315.71 & 17.444 \\
Exponential & 0.881 & 0881 & 256.925 & 2115.868 & 2117.151 & 195.683 & 66315.71 & 17.445 \\
Cubic & $\mathbf{0 . 9 1 0}$ & $\mathbf{0 . 8 9 9}$ & $\mathbf{2 0 7 . 4 4 5}$ & $\mathbf{2 0 3 7 . 6 0 9}$ & $\mathbf{2 0 4 0 . 1 7 5}$ & $\mathbf{1 4 6 . 7 7 4}$ & $\mathbf{4 3 0 3 3 . 8 1}$ & $\mathbf{1 3 . 9 8 4}$ \\
\hline
\end{tabular}

For coarse rice price the fitted cubic model is given as follows:

$$
\begin{array}{ll}
\mathrm{Y}_{1} & =52.463+12.169 \mathrm{t}-0.060 \mathrm{t}^{2}+0.002 \mathrm{t}^{2} \\
\mathrm{SE} & =(39.990)(0.788)(0.004)(0.00) \\
\mathrm{T} \text {-value } & =(1.312)(15.443)(17.236)
\end{array}
$$

Fig. 2 represents the fitted cubic model of coarse rice price from the time period July 1975 to December 2011.

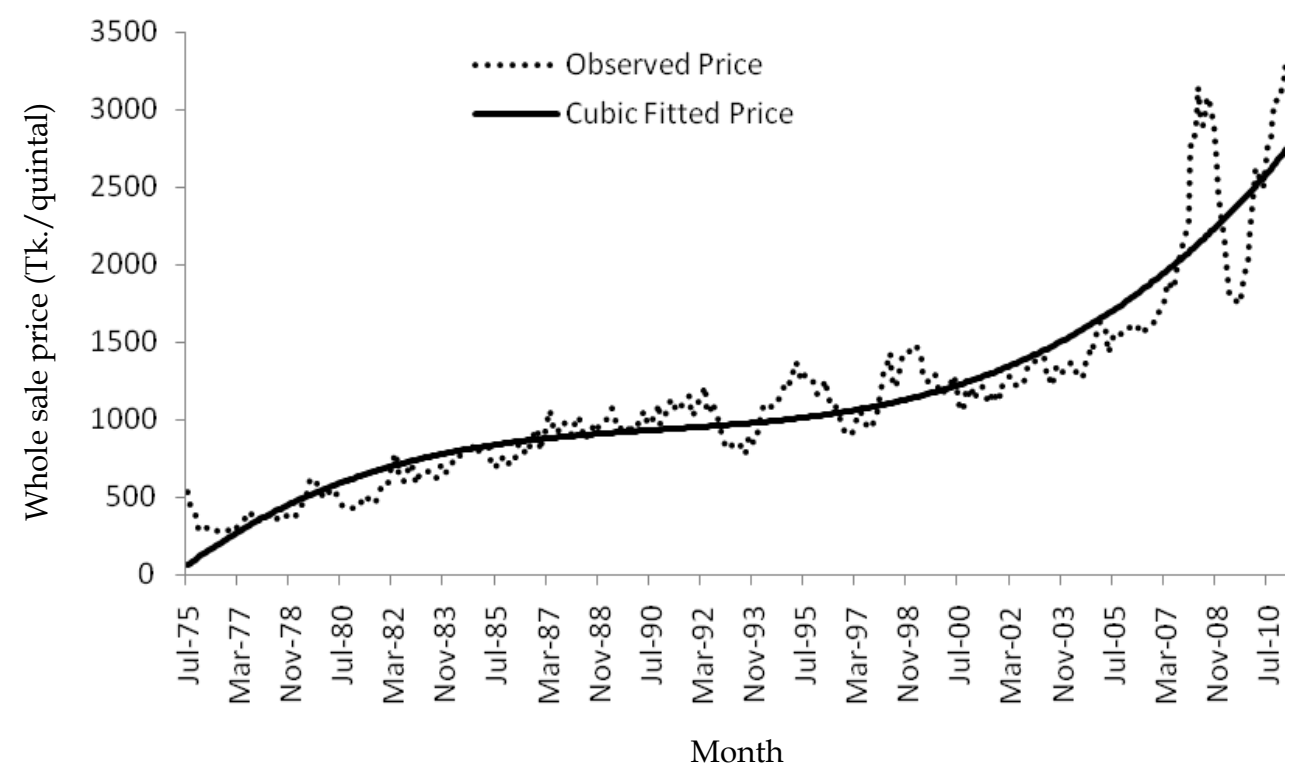

Fig. 2. Predicted wholesale prices of coarse rice by cubic model 


\section{Growth analysis}

Exponential and cubic growth rates are calculated using the formula in Table 1. The analysis revealed that the exponential growth rate of coarse rice price in Bangladesh during the study period was $0.40 \%[\beta \times 100=.004 \times 100.40 \%]$. It means that price grew on the average at this constant rate per year throughout the study period. This is inherent assumption of the exponential/compound growth model. But the best fitted model for coarse rice price in Bangladesh was cubic model, which assumes the growth of the series was not constant throughout the study period; instead it was dependent on time with a quadratic nature of variation.

The cubic growth rates of whole sale price of coarse rice are given in Fig. 3. It appears from the Fig. 3 that cubic growth rates varied from $0.68 \%$ to $4.03 \%$. It also reveals that during the $2^{\text {nd }}$ half of the seventies the growth rate was highest. After 1977 the growth rate started to decrease up to 1992. From 1993 the growth rates followed sudden ups and down and then an increasing trend in the end of the study period.

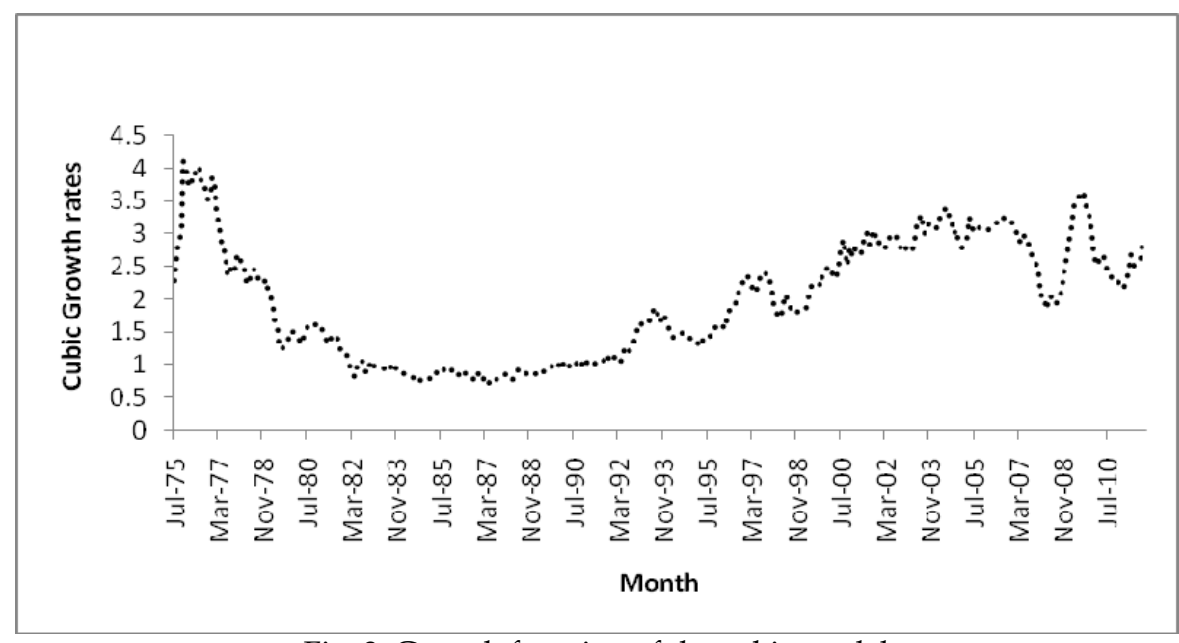

Fig. 3. Growth function of the cubic model

\section{Forecasting}

Wholesale prices of coarse rice are forecast with $95 \%$ confidence interval by using the fitted cubic model given in Appendix-1. A short term prediction period is considered from January 2012 to December 2013. One of the important limitations of making forecasting is that the forecasting error increases as the period of forecast increases. That is why short term forecast are considered as more reliable than long term forecast.

The analysis of the forecast values and confidence intervals given in Table 4 would reveal that forecasting errors are sufficiently small and consequently are not too large. The close examination of the analysis found that if the present growth rate continues the wholesale price of coarse rice in Bangladesh would be 3507.932 (taka/quintal) in the December 2013 with approximately plus/minus 425 (taka/quintal). 


\section{CONCLUSION}

Time series analysis comprises methods for analyzing time series data in order to extract meaningful statistics and other characteristics of the data. Time series forecasting is the use of a model to predict future values based on previously observed values. Among the two types of models (deterministic \& stochastic) that are used to describe the time series data, we have considered only the deterministic type of models in this study. These models are very quick, inexpensive, and capable of describing time series data adequately in many situations. In this study five deterministic time series models are considered. Among the different growth models the cubic model have the higher values of $R^{2}$ and adjusted $R^{2}$ with lower values of RMSE, AIC, BIC, MSE, MAE, and MAPE. Thus the model selection criteria suggest that cubic model of the time series performed better than the other models. So, the only deterministic model that may be used for describing the pattern of wholesale price of coarse rice in Bangladesh and making forecast with minimum forecast error from time to time for all time series data is the cubic model.

\section{REFERENCES}

Akaike, H. 1973. Information, Theory and Extension of The Maximum Likelihood Principle. $2^{\text {nd }}$ edition, Budapest. pp. 125-129.

BBS. 2009-2010. Statistical Yearbook of Bangladesh, Bangladesh Bureau of Statistics.

BER, 2010, Bangladesh Economic Review, Department of Finance, Ministry of Finance, Government of the People's Republic of Bangladesh, Dhaka.

Brennan, D. 1995. Final Research Report of the Bangladesh Foodgrains Management Operations Project: Policies for Stabilizing Rice Prices in Bangladesh. Chemonics International, Mimeo.

Food and Agricultural Organization, 2011. Bangladesh and FAO Achievements and success stories. Food and Agricultural Organization of United States, Rome.

Gujarati, D. N. 2003. Basic Econometrics, $4^{\text {th }}$ edn, MeGraw-Hill Inc., New York. pp. 23-256

Haque, M. E., Hossain, M. I. and Rahman, K. M. M. 2004. Searching for the best fitting deterministic model for innovative growth analysis and forecasting of rice production in Bangladesh. The Bangladesh Journal of Agricultural Economics, 27(1):1 5-35.

Haque, M. E., M. I. Hossain and Imam. M. F. 2005. The best fitting model for growth analysis and forecasting of fish production in Bangladesh. Journal of the Bangladesh Society for Agricultural Science and Technology, 2(1\&2): 227-234.

Pindyck, R. S and Rubinfeld, D. L. 1998. Econometric models and Economic Forecasts. $4^{\text {th }}$ edition. MacGrew-hill, New York, pp. 230-236.

Schwarz, G. 1978. Estimating the dimension of a model. Annals of Statistics, 6: 461-464.

Theil, H. 1961. Economic Forecast and Policy, $2^{\text {nd }}$ edn, North-Holland, Amsterdam. pp. 216-221. 


\section{Appendix - 1}

Table 1. Forecast price of coarse rice for the year 2012 and 2013 by cubic model

\begin{tabular}{|c|c|c|c|}
\hline \multirow[t]{2}{*}{ Month } & \multirow[t]{2}{*}{ Forecast value } & Lower limit of forecast & Upper limit of forecast \\
\hline & & \multicolumn{2}{|c|}{ 95\% confidence interval } \\
\hline Jan-12 & 2961.428 & 2545.283 & 3377.572 \\
\hline Feb-12 & 2983.331 & 2566.928 & 3399.735 \\
\hline Mar-12 & 3005.399 & 2588.729 & 3422.070 \\
\hline Apr-12 & 3027.632 & 2610.686 & 3444.578 \\
\hline May-12 & 3050.031 & 2632.801 & 3467.260 \\
\hline Jun-12 & 3072.595 & 2655.073 & 3490.118 \\
\hline Jul-12 & 3095.327 & 2677.503 & 3513.151 \\
\hline Aug-12 & 3118.226 & 2700.092 & 3536.361 \\
\hline Sep-12 & 3141.294 & 2722.840 & 3559.748 \\
\hline Oct-12 & 3164.530 & 2745.747 & 3583.314 \\
\hline Nov-12 & 3187.936 & 2768.814 & 3607.058 \\
\hline Dec-12 & 3211.512 & 2792.042 & 3630.983 \\
\hline Jan-13 & 3235.259 & 2815.430 & 3655.088 \\
\hline Feb-13 & 3259.177 & 2838.980 & 3679.375 \\
\hline Mar-13 & 3283.268 & 2862.691 & 3703.845 \\
\hline Apr-13 & 3307.531 & 2886.564 & 3728.497 \\
\hline May-13 & 3331.967 & 2910.600 & 3753.334 \\
\hline Jun-13 & 3356.578 & 2934.800 & 3778.356 \\
\hline Jul-13 & 3381.363 & 2959.162 & 3803.564 \\
\hline Aug-13 & 3406.324 & 2983.689 & 3828.958 \\
\hline Sep-13 & 3431.460 & 3008.380 & 3854.540 \\
\hline Oct-13 & 3456.773 & 3033.236 & 3880.311 \\
\hline Nov-13 & 3482.264 & 3058.257 & 3906.271 \\
\hline Dec-13 & 3507.932 & 3083.443 & 3932.420 \\
\hline
\end{tabular}

